\title{
MINIMALLY INVASIVE METHODS IN TREATMENT OF COMPLICATED FORMS OF CENTRAL LUNG CANCER
}

\author{
Vladislav Severgin \\ Department of reconstructive and rehabilitative medicine \\ Odessa National Medical University \\ 2 Valihovsky per., Odessa, Ukraine, 65082 \\ Gedeon241@rambler.ru \\ Sergei Prohoda \\ Odessa oncologic hospital \\ 26 Nejdanova str., Odessa, Ukraine, 65056 \\ Aleksey Prohoda \\ Odessa National Medical University \\ 2 Valihovsky lane, Odessa, Ukraine, 65082
}

\begin{abstract}
Despite certain achievements in lung cancer treatment, the essential number of patients is subjected to palliative and symptomatic treatment. Hemoptysis addition is the one of most heavy symptoms of unresectable lung cancer. No less heavy complication is an atelectasis and hypoventilation of a lobe or a whole lung, which clinical image is attended by respiratory failure phenomena or association of purulent-septic pneumonia. The combination of endoscopic hemostasis with roentgen endovascular embolization of bronchial arteries (REEBA) allows to increase patients' live quality and to prolong it for some time.

In the clinic REEBA has been done in 121 patients with unresectable forms of lung cancer. The causes of surgical treatment refusal were a widespread tumor process, age, and severity of associated pathology.

Hemostasis was achieved in 112 patients. A relapse of pulmonary bleeding was observed in 11 patients, who underwent the repeated REEBA. Lethal outcome was observed in 5 cases. Hemostasis was ineffective in 9 patients.

Thus, the experience of using REEBA and endoscopic hemostasis at complicated forms of unresectable lung cancer allows to increase the life quality and in further to realize chemoradial therapy that gives a possibility to prolong a patient's life.
\end{abstract}

Keywords: pulmonary bleeding, lung cancer, embolization of bronchial arteries.

\section{Introduction}

The urgency of the problem of lung cancer is connected with the growth of morbidity, high lethality and bad treatment results. Lung cancer occupies the first place among men in Ukraine, and it remains a leader among causes of death from malignant tumors.

Despite certain achievements in lung cancer treatment, the essential number of patients is subjected to palliative and symptomatic treatment. The hidden course of a tumor process and long absence of evident clinical manifestations mainly determine great complications of the modern lung cancer diagnostics. The experience shows that most patients with firstly diagnosed diseases visit a doctor at already widespread tumor process that doesn't allow the radical treatment. The presence of severe complication of the tumor process in them doesn't allow to apply chemotherapy or radial therapy. Thus, among patients, admitted at stationary treatment in different oncological and surgical medical institutions, III and IV stages of disease are established in 40-75\%, at that IV stage - in $12 \%[1,2]$. At the same time the presence of concomitant pathology and old age don't give a possibility to realize the radical surgical intervention at the absence of inoperability signs.

An addition of hemoptysis or pulmonary bleeding is the one of most complicating symptoms of cancer inoperability [3]. A bleeding at lung cancer as an initial symptom of disease is detected in $20 \%$ of patients and at the final stage of disease a bleeding appears in $60 \%$ of patients [4]. Lung cancer causes pulmonary bleeding in the period of necrosis and destruction of a bronchus wall. As a result of malignant process there takes place a break of newly created thin-walled lacuna 
and the net of small vessels that don't have an elastic coat [5]. Thus, a bleeding at lung cancer indicates an essential lesion of big bronchi or necrotic changes of a lung parenchyma.

No less dangerous complication is an atelectasis and hypoventilation of a lobe or a whole lung, which clinical image is attended by respiratory failure phenomena or association of purulent-septic pneumonia [6].

An important role in the pathogenesis of pulmonary bleeding is played by an arrosion of a vessel by a tumor, break of vascular wall, blood access in alveoli from bronchial arteries.

Last time the methods of endoscopic recanalization of tumor stenosis and hemostasis of a bleeding tumor using a laser radiation, plasma flows, electrocoagulation at treating complicated forms of lung cancer appeared [7]. Roentgen endovascular embolization of bronchial arteries (REEBA) is used for these aims more seldom [8] and the method of radiofrequency thermoablation of a tumor bronchus stenosis (RFA) is practically not used [9]. The method of radiofrequency ablation was used for the first time for a liver tumors ablation. The first experimental works were published in 80 years of 20 century [10]. RFA method is realized by introduction of the special atraumatic electrode in a tumor and influence of current with the frequency $450-500 \mathrm{kHz}$ on it. As a result the tumor tissue is heated to the temperature $60-90{ }^{\circ} \mathrm{C}$ that conditions irreversible processes in cells. A tumor is necrotized [11].

The offered method of endobronchial RFA using the electrode, elaborated by us, is very effective in the treatment of tumor stenosis of bronchi and trachea.

The introduction of such non-standard technologies as REEBA and endoscopic recanalization of a tumor stenosis of respiratory tracts, RFA of tumors allowed to provide conditions for giving help to patients [12].

At this message we want to share own experience of using endovascular and endoscopic methods in the treatment of lung cancer complicated forms.

\section{Aim of research}

The aim of research was in elaboration of the complex method of palliative treatment of patients with the central lung cancer, complicated by hemoptysis and tumor bronchus stenosis. The use of this method allows to improve not only patients' life quality by its term also.

\section{Materials and methods}

In the clinic REEBA with bronchoscopic recanalization and hemostasis has been done in 121 patients with unresectable forms of lung cancer, complicated by hemoptysis, pulmonary bleeding, atelectasis of a central or lobe bronchus. The analyzed group included 84 men and 37 women. Patients' distribution by stages was the following: IIIa -25 , III -58 , IV -38 . The causes of surgical treatment refusal were a widespread tumor process, age and severe associated pathology and often these both causes. Among associated pathologies the main ones were: myocardium infarction in an anamnesis, complicated by postinfarction cardiosclerosis, heart rate disorders, disorders of cerebral blood circulation, respiratory or heart failure, COLD. Three patients have been previously operated in different medical institutions because of the central lung cancer. In two cases the cause of a bleeding is a tumor relapse in bronchial stump. 74 patients had an ordinary hemoptysis and little pulmonary bleeding, attended by blood secretion in volume up to $100 \mathrm{ml}$ a day. The expressed pulmonary bleeding was observed 47 patients and was $200-400 \mathrm{ml}$ a day.

REEBA was realized on the apparatus Allara Xper FD - 20 "Phillips". After catherization of a femoral artery according to Seldinger, the catheter "Cobra" 5F2 was inserted in the thoracic aorta. Two patients underwent catherization of the right radial artery because of Leriche syndrome in their anamnesis. Then the angiography with catherization and contrasting of bronchial arteries on the side of injury was realized. After revelation and catherization of bronchial arteries that nourish the tumor, the working catheter was inserted in it by "Transend" conductor. It was used for vessels embolization by "Italamp" emboli with sizes $420-750 \mathrm{~mm}$. The criterion of embolization effectiveness was an absence of bronchial arteries contrasting in the tumor zone [13].

According to the literary data, the most frequent complications at REEBA realization were: myelitis, appeared as a result of emboli hitting the spinal vessels that anastomosed with bronchial 
arteries and a pain syndrome, connected with ischemia due to bronchial arteries embolization. Such complication as myelitis was not observed in our research, because we always inserted the catheter in bronchial arteries selectively. A pain syndrome was observed in almost all patients, but it was stopped by ordinary analgesics and was not long.

The methods of endoscopic RFA coagulation and recanalization of a tumor using the bronchoscope were the following. In almost all cases we used a local anesthesia and 2-channel fibrobronchoscopes "Olympus" and "Pentax". In 3 patients, who underwent fibrobronchoscopies under local anesthesia very badly, we used a general anesthesia. They underwent the rigid bronchoscopy using Fridel bronchoscope with inserted fibrobronchoscope with the mono-polar electrode. Lidocaine $2 \%-20,0$ was used as a local anesthetic. After the assiduous anesthesia of respiratory tracts, the thin electrode was conducted to the tumor through the working channel of bronchoscope. For these aims at the beginning there was used the electrode for cardioablation, connected to the apparatus FOTEK 150. In most cases of operative interventions we used the mono-polar electrode, elaborated by us, that allowed to decrease the number of interventions from 4-5 to $2-3$. The working characteristics of FOTEK 150 are: capacity 30 Watt, exposition time 20-30 seconds. The effectiveness criterion was a bronchus recanalization. In cases, when we used endobronchial RFA under local anesthesia, all patients were active immediately after finishing the operative intervention. In cases, when we used general anesthesia, patients needed observation during 2-3 hours.

\section{Results of research}

As a result of REEBA and endoscopic recanalization we succeeded in stopping a bleeding and hemoptosis in 112 (92,5\%) patients. Hemostasis was ineffective in 9 (7,5\%) patients. The causes were in an impossibility to realize the embolization of vessels that nourish a tumor because of anatomic features of vessels, anamostoses between the small and large circle of lung blood supply. At the same time the important role was played by the complication in endoscopic coagulation of a tumor surface at upper lobe localization. A lethal result of the long bleeding was observed in 5 cases. The acute myocardium infarction appeared in 1 patient with a hollow form of lung cancer in early postoperative period, in other 4 cases the cause of lethal result was the long bleeding from the breaking tumor, and a source of this long bleeding were vessels of the small circle of blood circulation. In 5 cases we succeeded in radical operative interventions after REEBA, endobronchial RFA and radial therapy. We realized one pneumonectomy and four lobectomies.

Until the present time there are no doubts about REEBA effectiveness in the treatment of pulmonary bleedings, even massive ones [13]. At the lung cancer a bleeding of massive type is seldom that allows to use REEBA successively for its stop [14]. At an angiography at REEBA there was revealed the widened and deformed vascular net in the tumor zone, endovazation of contrast, widening of arteries with a pathological bypassing.

REEBA was considered effective at the complete absence of contrasting of arteries that take part in tumor blood supply [15]. REEBA must not be realized at wide pathologic anamostoses that make this procedure dangerous that is proved by other authors [16]. The absolute contraindication for REEBA is anamostoses with spinal, vertebral and neck arteries.

The stop of bleeding allowed us to realize the chemoradial treatment of 93 patients. The rest 28 did not undergo the chemoradial therapy because of a heavy concomitant pathology, continuous bleeding or low functional rates. Bleeding relapses were observed in 11 patients, the causes were in the further growth of cancer tumor and its continuous disintegration. The period of observation over patients was 10 months.

\section{Discussion of results}

The experience of endoscopic hemostasis at the lung cancer demonstrated the effectiveness of this method at unessential bleedings and hemoptysis. Massive blood supply in respiratory tracts doesn't allow to control a tumor coagulation process and makes this method ineffective [17].

The use of endobronchial RFA method allowed to attain the good effect of recanalization and coagulation. But at more intensive pulmonary bleedings this method of hemostasis is not effective. Previously at using diathermocoagulation for ceranalization of tumor stenoses, the pulmonary 
bleeding in $10 \%$ of patients not only did not stop but intensified. Our experience testifies that annually at realization of diathermocoagulative recanalization of bronchial and tracheal tumor stenoses we had 1-2 lethal cases, connected with an intense pulmonary bleeding and asphyxia of patients.

In the aforesaid connection all patients underwent REEBA for the prophylaxis of pulmonary bleeding at endobronchial recanalization. It allowed not only stop the pulmonary bleeding but also decelerate the tumor growth by closing the main vessel of its blood supply.

All aforesaid allowed us to elaborate the method of combined hemostasis at lung cancer. At the beginning patients underwent REEBA then the endoscopic hemostasis method was used. The separate use of endoscopic hemostasis is possible at central forms of lung cancer, when the bleeding tumor is localized in main or lobe bronchi. At injuring more peripheral parts of bronchial tree, especially at hollow cancer forms, REEA was the single treating method, because of absence of the tumor stenosis and atelectasis of the main or lobe bronchus [18].

According to the data of several authors, the mean life duration after endoscopic recanalization of tumor stenoses, caused by a malignant process, doesn't exceed 4,5 moths [19]. Due to the offered method we not only improved patient's live quality but also prolonged it up to 10 months. At the same time the use of embolization and radiofrequency ablation allowed in several cases to realize the course and radio- or chemotherapy that also allowed to prolong patients' life [20]. In several cases we realized REEBA repeatedly in the little number of patients. It was connected with the hemoptysis relapse. On the control angiogram we saw that the tumor is supplied with blood due to collateral branches of intercostal arteries, placed upper and lower than the tumor. Tumor sizes in all cases were essentially less than at the beginning of treatment. In such cases we realized embolization of intercostal arteries, which supplied the tumor with blood.

At control fibrobronchoscopies on 3-4th day we observed the started tumor necrosis. More often the purulent endobronchitis with secretion of the great amount of purulent sputum appeared in patients on 5th day. At the same time the temperature rise was observed in many patients, intoxication symptoms appeared. In this connection we realized the symptomatic, anti-inflammatory and antibacterial therapy before endobronchial RFA. After improving a patient's state, approximately on 2-3th week, we stated the radio- or chemotherapy.

Last time bronchoscopes appeared on the base of the clinic of Odessa national medical university and Odessa Regional oncologic dispensary that allowed not only to realize RFA of bronchial tumors effectively, but also to make endophotos that testify to the effectiveness of the offered method.

At injuring more peripheral parts of bronchial tree, especially at hollow lung cancer forms, REEBA was the single treating method that allowed not only to stop a bleeding but also to decrease a speed of tumor growth. Thus, the experience of REEBA and endoscopic hemostasis use at complicated unresectable forms of lung cancer allows to make the following conclusions.

\section{Conclusions}

1. REEBA is a main way of hemostasis at complicated lung cancer forms. At central forms of lung cancer, complicated by bleedings and bronchus atelectasis, it is expedient to combine REEBA with endoscopic laser, electrocoagulation, RFTA of a tumor.

2. The use of radiofrequency thermoablation method for eliminating bronchial atelectasis needs further clinical studies.

3. The expedience of the aforesaid methods as a stage of preparation for chemoradiotherapy needs a further study.

\section{References}

[1] Boyko, Yu. V., Avdos'ev, A. G. (2008). Krasnoyaruzhskiy Himioembolizaciya bronhial'nyh arteriy u bol'nyh rakom lekgogo, oslozhnennym legochnym krovotecheniem. Onkologiya, 10 (3), 350-353.

[2] Granov, A. M., Davydov, M. I. (2013). Intervencionnaya radiologiya v onkologii. Saint Petersburg: Foliant, 543.

[3] Grigor'ev, E. G., Kvashin, A. I., Atamanov, S. A. et. al. (2006). Rentgenendovaskulyarnaya diagnostika i lechenie legochnogo krovotecheniya. Grudnaya i serdechno-sosudistaya hirurgiya, 4, 57-62. 
[4] Shipulin, P. P., Severgin, V. E., Ageev, S. V. et. al. (2011). Endoskopicheskaya hirurgiya trahei i bronhov. Ukrains'kiy zhurnal maloinvazivnoi ta endoskopichnoi hirurgii, 15 (4), 34-37.

[5] Chernekhovskaya, N. E., Korzhova, I. Yu., Andreev, V. G., Povalev, A. V. (2011). Legochnye krovotecheniya. Moscow: Med-press-inform, 127.

[6] Chang, L. F., Fung, E. P. Y., Hon, T. Y. W. et. al. (2005). Bronchial artery embolisation for acute massive haemoptysis: retrospective study. I. H. K. Coll Radiol, 8, 15-19.

[7] Shigemura, N., Wan, I. Y., Yu, S. C. H., Wong, R. H., Hsin, M. K. Y., Thung, H. K. et. al. (2009). Multidisciplinary Management of Life-Threatening Massive Hemoptysis: A 10-Year Experience. The Annals of Thoracic Surgery, 87 (3), 849-853. doi: 10.1016/j.athoracsur.2008.11.010

[8] Trahtenberg, A. H., Chisov, V. I. (2000). Klinicheskaya onkopul'monologiya. Moscow: GEOTAR, 600 .

[9] Marasso, A., Bernardi, V., Gai, R., Gallo, E., Massaglia, G. M., Onoscuri, M., Cardaci, S. B. (1998). Radiofrequency resection of bronchial tumours in combination with cryotherapy: evaluation of a new technique. Thorax, 53 (2), 106-109. doi: 10.1136/thx.53.2.106

[10] Severgin, V. E., Shipulin, P. P., Agrahari, A. et. al. (2014). Maloinvazivnoe lechenie neoperabel'nyh form raka lyogkogo oslozhnennyh lyogochnym krovotecheniem. Ukrainskiy zhurnal maloinvazivnoy i endoskopicheskoy hirurgii, 4, 9-12.

[11] Brokx, H. A. P., Risse, E. K., Paul, M. A., Grunberg, K., Golding, R. P., Kunst, P. W. A. et. al. (2007). Initial bronchoscopic treatment for patients with intraluminal bronchial carcinoids. The Journal of Thoracic and Cardiovascular Surgery, 133 (4), 973-978. doi: 10.1016/j.jtcvs.2006.12.013

[12] Okiror, L., Jiang, L., Oswald, N., Bille, A., Rajesh, P., Bishay, E. et. al. (2015). Bronchoscopic Management of Patients With Symptomatic Airway Stenosis and Prognostic Factors for Survival. The Annals of Thoracic Surgery, 99 (5), 1725-1730. doi: 10.1016/j.athoracsur.2015.01.061

[13] Park, J. S., Lee, M., Kim, H. K., Choi, Y. S., Kim, K., Kim, J. et. al. (2011). Primary leiomyoma of the trachea, bronchus, and pulmonary parenchyma - a single-institutional experience. European Journal of Cardio-Thoracic Surgery, 41 (1), 41-45. doi: 10.1016/j.ejcts.2011.03.051

[14] Severgin, V. E., Shipulin, P. P., Agrahari, A. et. al. (2015). Vozmozhnosti primeneniya endovaskulyarnogo gemostaza pri lechenii legochnyh krovotecheniy. Klinicheskaya hirurgiya, 6, 46-48.

[15] Severgin, V. E. (2016). Methods of Palliative Treatment for Complicated Forms of Lung Cancer. 52 Annual Meeting The Society of Thoracic Surgeons. Phoenix, 38.

[16] Chhajed, P. N., Tamm, M. (2005). Will There Be a Role for Bronchoscopic Radiofrequency Ablation? Journal of Bronchology, 12 (3), 184. doi: 10.1097/01.laboratory.0000163024.10160.9a

[17] Kessel, D., Ray, C. (Eds.) (2009). Transcatheter Embolization and Therapy. London: Springer, 505. doi: 10.1007/978-1-84800-897-7

[18] Mauro, M. A., Murphy, K. P. J., Thomson, K. R., Venbrux, A. C., Zollikofer, C. L. (2008). Bronchial artery embolization. Philadelphia: Elsevier, 931-938.

[19] Suvorova, Yu. V., Tarazov, P. G., Mus, V. F. (2011). Embolizaciya bronhial'nyh arteriy u bol'nyh rakom lyogkogo oslozhnennogo krovotecheniem. Mezhdunarodnyy zhurnal intervencionnoy kardioangiologii, 24, 58-59.

[20] Steppert, C., Fuchs, F., Neurath, M. (2016). Endobronchial radiofrequency ablation for veruccous carcinoma of the trachea. European Respiratory Journal, 48, 342-345. doi: 10.1183/13993003.congress-2016.pa3842 